The Open Civil Engineering Journal
CrossMark
Content list available at: www.benthamopen.com/TOCIEJ/
DOI: $10.2174 / 1874149501711010861$

RESEARCH ARTICLE

\title{
Reinforcement Technology for Foundation Beams of Shear Wall Specimens and Example Analysis
}

\author{
Jiliang Liu ${ }^{1}$, Huibin $\mathrm{Xu}^{1}$, Ruiwei $\mathrm{Li}^{1}$, Qingchi Zhang ${ }^{1}$ and Mingjin $\mathrm{Chu}^{2, *}$ \\ ${ }^{1}$ School of Civil Engineering, Yantai University, Yantai, 264005, China \\ ${ }^{2}$ School of Civil and Transportation Engineering, Beijing University of Civil Engineering and Architecture, Beijing \\ 100044, China
}

Received: December 20, 2016

Revised: February 15, 2017

Accepted: March 25, 2017

\section{Abstract: \\ Background:}

The accuracy of test result could be affected by the cracking of foundation beam in the pseudo-static test of shear walls.

\section{Objective:}

In the paper, the reinforcement method combing external pre-stress method and adding steel bars method was used to reinforce the foundation beam.

\section{Conclusion:}

The study proved that the reinforcement method could reduce the strain of longitudinal steel and slow down the cracking of foundation beam. So that,the method can gain expected goal and offer some help for similar situations.

Keywords: Shear wall, Pseudo-static test, Foundation beam, Cracking, Pre-reinforcement, Steel bars method.

\section{INTRODUCTION}

Pseudo-static test is an important method to study the seismic behavior of shear walls [1]. The shear wall specimen in the test is shown in Fig. (1). The foundation beam in the bottom of the specimen is simplified as the fully fixed end of the shear wall. In order to resist the moment and shear force of the shear wall, the foundation beam should have enough rigidity and good crack resistance. In recent years, full-size specimens were used in order to obtain accurate test data because shear walls had better bearing capacity and foundation beams were easy to crack, so the foundation beam was designed carefully in this paper.

The current calculation method of foundation beam is difficult to analyze the complicate force state of the foundation beams, such as bending moment, vertical load coming from the upper interior components, and the horizontal load coming from the horizontal limiting displacement system. So, many designs about foundation beam depend on experience, and the disadvantaged case cannot be avoided. For example, there were some diagonal shear cracks in the foundation beam, because of strength shortage. Therefore, it is significant to reinforcement foundation beam by proper technical scheme. In the paper, external pre-stress and redundant steel bars were effectively used to reinforce the foundation beam.

\footnotetext{
* Address correspondence to this author at the School of Civil and Transportation Engineering, Beijing University of Civil Engineering and Architecture, Beijing 100044, China; Tel: +86 10 68321834; Fax: +86 10 68321834; E-mail: housind@126.com
} 


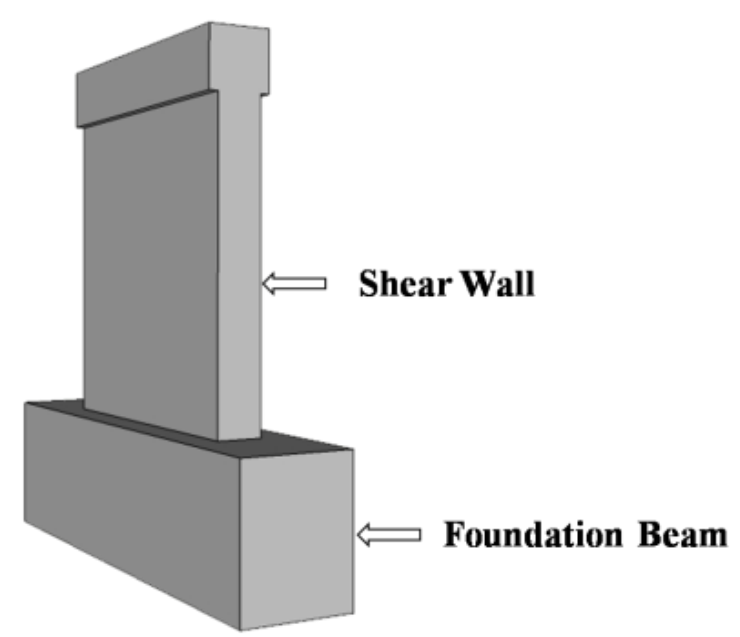

Fig. (1). Schematic diagram of shear wall specimens.

\section{FAILURE MODE OF FOUNDATION BEAM}

The experiment of shear wall includes bending test and shear test. The bearing capacity of shear wall in bending test is very low and the foundation beam can be easy to meet demand, because the main crack and deterioration of shear walls concentrated in the plastic hinge region. However, the foundation beam cannot be easy to meet the demand in the shear test because of high bearing capacity and high stiffness of the shear wall. The main failure mode of foundation beam includes four pars as following.

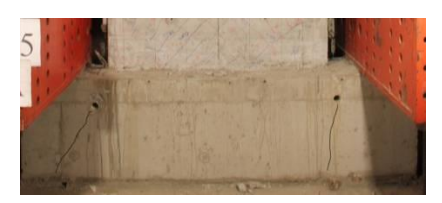

a. Vertical cracking

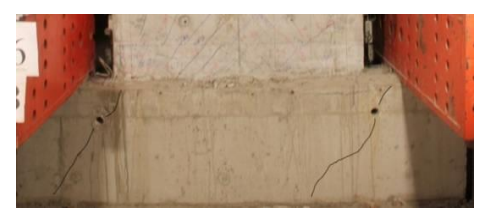

b. Diagonal cracking

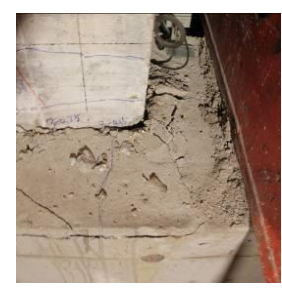

c. Anchorage invalidation of longitudinal bars in the edge element

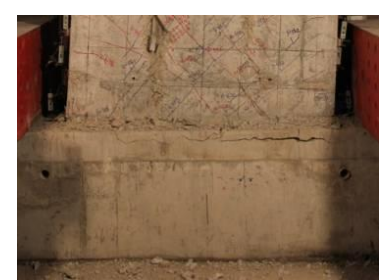

d. Cracking along steel bars

Fig. (2). Failure process of foundation beam. 
1. Vertical crack: If the cross section of foundation beam is very small, there were some vertical cracks, and if the longitudinal reinforcements are less, the crack width was large in the foundation beam. The typical crack is shown in Fig. (2a).

2. Diagonal crack: The foundation beam outside of the shear wall can be seemed as a corbel, when the strength of concrete is insufficient and the dimension of cross section does not meet the requirements, diagonal cracks appear and extend down in a degree of 45. The typical crack is shown in Fig. (2b). After the diagonal cracks appearing, diagonal cracks intersect longitudinal bars of the edge element in the shear wall. Under the cyclic load, anchorage invalidation of longitudinal bars in the boundary element is easy to occur. The typical condition of anchorage invalidation is shown in Fig. (2c).

3. Cracking along bars: Longitudinal bars in the foundation beam are distributed intensively. Under the cyclic load, bond anchorage failure may occur, and then form the cracking along bars which is shown in Fig. (2d).

\section{REINFORCEMENT MEASURE OF FOUNDATION BEAM}

The actual concrete strength of the shear wall reached $45 \mathrm{MPa}$ in the test of studying the shear performance of a new-typed shear wall structure, while the design strength which is only $30 \mathrm{MPa}$. So, the bearing capacity of shear wall was excellent, and it was difficult to match to the crack capacity of foundation beam. The conditions of diagonal cracking in the foundation beam and anchorage invalidation of longitudinal bars in the boundary element appear, and failures along longitudinal bars in the foundation beam occur for some specimens. Therefore, the reinforcement for foundation beams is very necessary.

Fig. (3) shows the specimen size and reinforcement situation of the foundation beam. Each side of the foundation beam exceeds the shear wall $500 \mathrm{~mm}$ and the cross section of the foundation is $500 \mathrm{~mm}$ in width and $650 \mathrm{~mm}$ in height. The measured concrete strength is $32 \mathrm{MPa}$. Eight bars whose diameter was $25 \mathrm{~mm}$ were placed at the top of the foundation beam, and four bars whose diameter was $20 \mathrm{~mm}$ were distributed in the middle. Eight bars whose diameter was $25 \mathrm{~mm}$ were set at the bottom of the foundation beam. The diameter of stirrup was $10 \mathrm{~mm}$ rebar the design yield strength of all the steel bars is $360 \mathrm{Mpa}$, and the distance of two stirrups was $100 \mathrm{~mm}$.
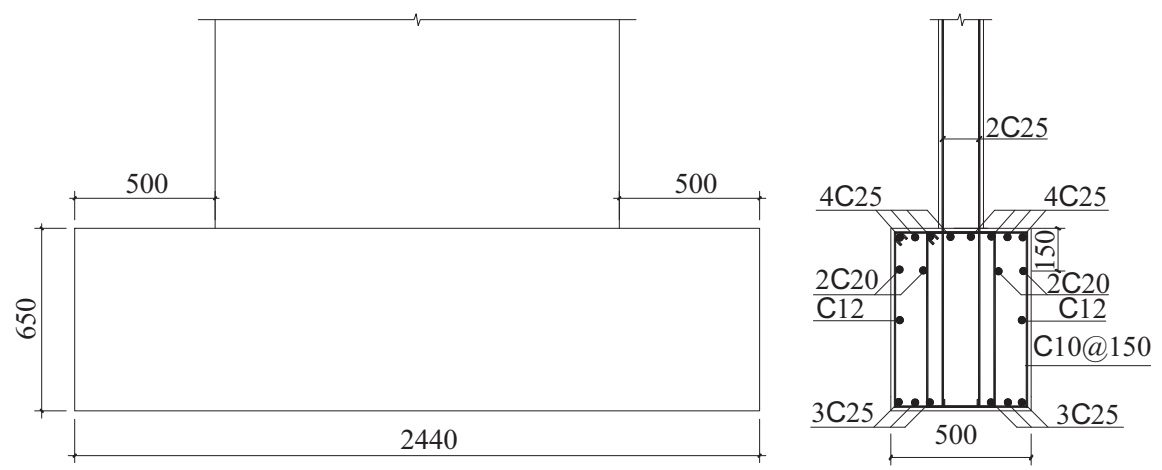

Fig. (3). Specimen size and reinforcement situation of the foundation beam.

The methods of enlarging section and sticking carbon fiber were considered to reinforce the foundation beam at first during the layout of reinforcement [2,3]. But, enlarging section method with high reliability was hard to construct and apply due to the limitation of laboratory condition [4]. The sticking carbon fiber method could increase the shear capacity and limit the development of cracks, while it could not increase the crack capacity obviously, and it needs too much carbon fiber to gain the reinforcement goal [5].

Therefore, the external prestress method combining with adding steel bar method was used to reinforce the foundation beam with consideration of the condition of laboratory.

\subsection{External Pre-stress:}

Applying prestress is an effective measure to increase the crack capacity of concrete. This method can make the foundation beam remain pre-compressive stress before bearing the load, and can partially offset tensile stress under the load.

The external prestress of reinforcement set is shown in Fig. (4). The reinforcement system includes steel plate, steel 
screws, counter-force steel beams and jacks with load capacity of 200T. Steel screws and counter-force steel beams have adequate stiffness. The diameter of steel screws is $80 \mathrm{~mm}$. Counter-force steel beams are steel box with $400 \mathrm{~mm}$ in height. The reinforcement set was applied as following. Two steel screws were set respectively in the front and the back of foundation beam, and both ends of steel screws were anchored to counter-force steel beams by nuts. One end of counter-force steel beams was directly supported by the foundation beam and the other end was supported by the jack. By this method, the reinforcement set thereby formed a self-balancing system as shown in Fig. (4). Between the jack and the foundation beam, a steel backing plate whose cross section is $500 \mathrm{~mm}$ in height, $370 \mathrm{~mm}$ in width and $60 \mathrm{~mm}$ in thickness was replaced to make the load disperse uniformly. The same as to between counter-force steel beam and foundation beam.

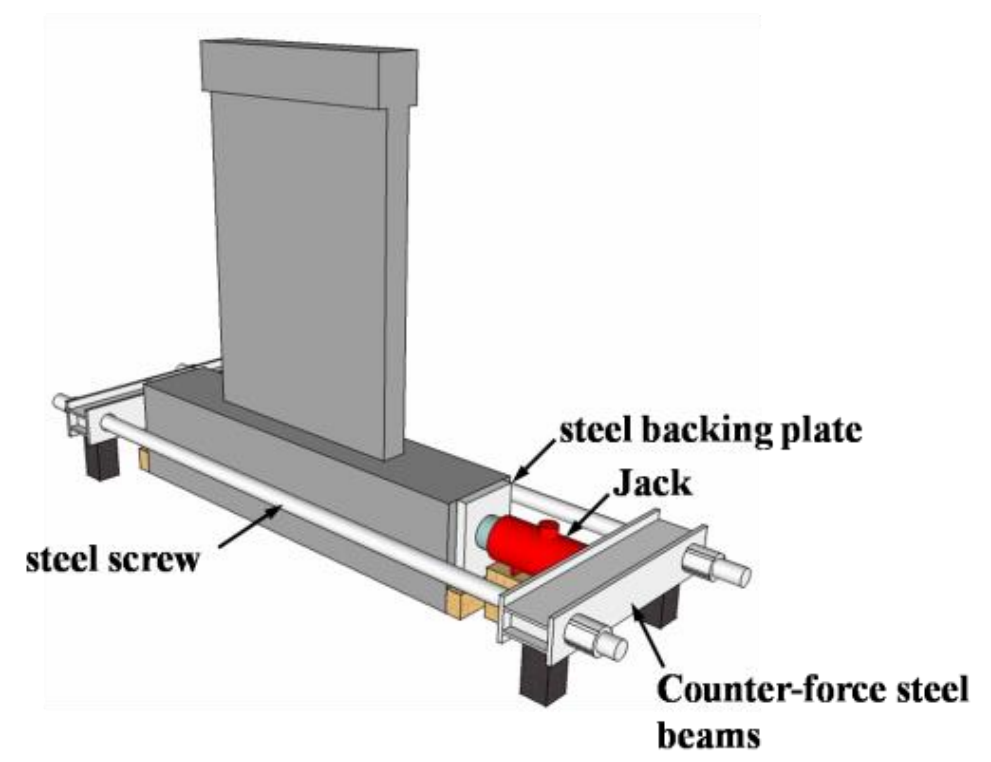

Fig. (4). Schematic diagram of reinforced foundation beam by external pre-stress.

Before the test, load was applied by a jack and constant for 12 hours. During the test, the compression by jack decreased because of concrete creep was often increased to predetermined value. The applied loading value of the jack was determined by the strength of foundation beam concrete, the bearing capacity of the shear wall, and so on. The compressive stress of the foundation beam cannot exceed $20 \%$ of the concrete axial compressive strength.

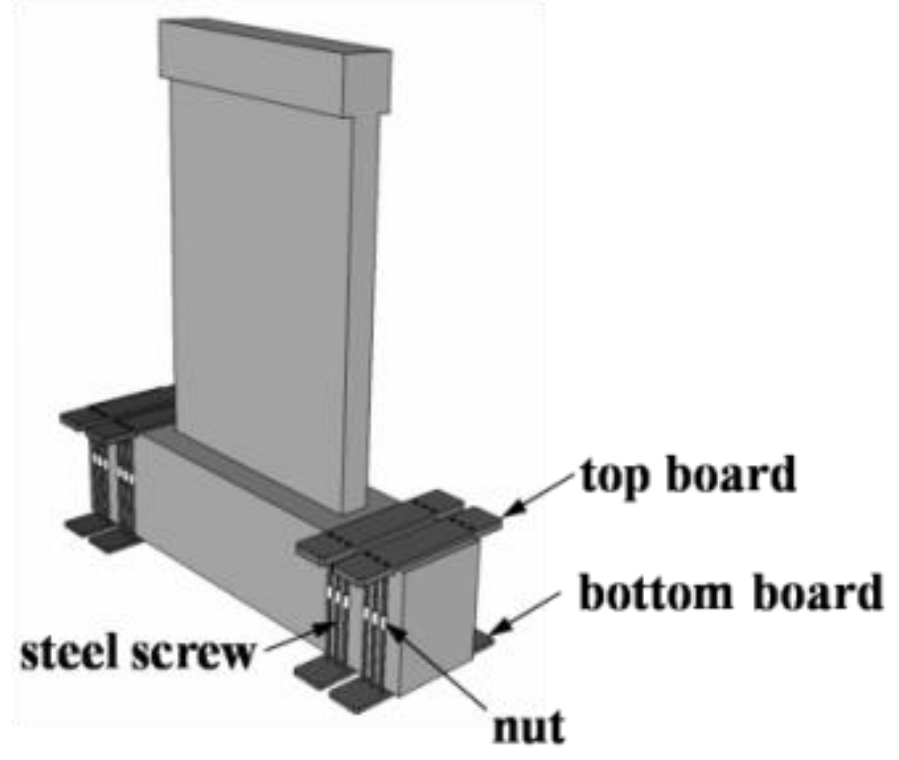

Fig. (5). Schematic diagram of reinforced foundation beam by adding steel bars.

When pre-stress method was used to pre-reinforce the foundation, the pre-stress load applied to the foundation beam 
by the jack could be adjusted according to concrete conditions of the test. The method could take full advantage of equipment conditions in laboratory, and easy to install and remove.

\subsection{Adding Steel Bars:}

The external pre-stress method could greatly decrease the crack of the foundation beams, but crack still appeared to some specimens. To limit the development of cracks, redundant steel bars were used for the reinforcement which is shown in Fig. (5). The redundant steel bars included 4 reinforcement units, and each reinforcement unit consisted of a top board, a bottom board, 6 steel screws and connection nuts. The thickness of the boards was $40 \mathrm{~mm}$. At each end of the board, 4 threaded holes were replaced along one line. The diameter of the steel screw was $20 \mathrm{~mm}$, which was full thread. Every steel screw consisted of two parts connected by nuts which were equally reverse. The upper and lower of the steel screw were through into threaded holes of the boards. The top and bottom end of steel screws cannot protrude from the boards because of the upper pressure beam and the lower floor. During the set installed, mortars were used to leveling between board and pressure beam at first, then installed steel screw to make the board arched. It would restore to plane state after the pressure beam installed.

Pre-tension was produced in the steel screws, and it can enhance the reinforcement effect.

The redundant steel bars were simple and the reinforcement units could be used repeatedly. By using pre-tension produced in the steel screws of the shear wall test system, the effect of reinforcement can be ensured.

\subsection{The Effect of Reinforcement:}

The reinforcement method combining the external pre-stress with adding steel bars reached expected aims with good reinforcement effect. The main aims are as follows.

1. It increased greatly the cracking capacity of foundation beam, and most specimens can be avoided to crack. The cracking loads are greatly increased of some cracking specimens. By using the external pre-stress method, the initial tensile stress was $5 \mathrm{MPa}$ being applied in foundation beam. The bending capacity of the bottom in the shear wall was more than $2500 \mathrm{kN} \cdot \mathrm{m}$. Of course, it was more than the bending capacity before prereinforcement, and the reinforcement effect was significantly.

2. It limited the crack development of foundation beam effectively and change the crack development direction. After reinforcement, there was no flexible crack on the foundation beam. The degree of diagonal cracks was changed from $45^{\circ}$ before reinforcement to $25^{\circ}$ after reinforcement. The width of diagonal cracks decreased from up to $1 \mathrm{~mm}$ to $0.1 \mathrm{~mm}$ or so.

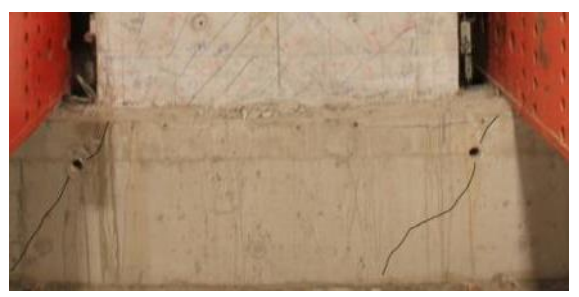

a. Before reinforcement

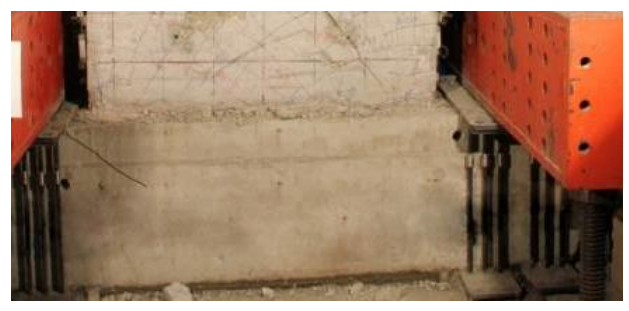

b. After reinforcement

Fig. (6). Crack development of foundation beam before and after reinforcement.

3. It avoided the failures of anchorage invalidation of longitudinal bars and longitudinal crack. The intersection 
position between the diagonal cracks of foundation beam and the longitudinal bars in boundary elements was usually at the lower position of foundation beam before reinforcement. The position changed to the point with the distance of $150 \mathrm{~mm}$ from the top surface of foundation beam after reinforcement, which is shown in Fig. (6). The lengths of the longitudinal bars below diagonal cracks were greatly increased, and the quantity of diagonal cracks was greatly decreased after the reinforcement. Therefore, the failure mode of anchorage invalidation of longitudinal bars in boundary elements had been avoided.

\section{CONCLUSION}

In the paper, the reinforcement method combing external pre-stress and adding steel bars was proposed to solve the crack problem of the foundation beam with full size shear walls. Some conclusions can be drawn below.

1. The reinforcement method could be installed simply, and the set could be reused. The reinforcement technology was easy and could be popularization and application.

2. The effect of reinforcement method was significant. The reinforcement method can ensure the foundation beam to reach the expect aim.

\section{CONSENT FOR PUBLICATION}

Not applicable.

\section{CONFLICT OF INTEREST}

The authors declare no conflict of interest, financial or otherwise.

\section{ACKNOWLEDGEMENTS}

The authors are grateful to the support of National Science Foundation of China (Grant No. 51378450, 51508490).

\section{REFERENCES}

[1] Ministry of Housing and urban-Rural Development of the People' Republic of China, "JGJ101-96 specificating of testing methods for earthquake resistant building", 1997.

[2] J. Liu, J. Wang, and N. Ding, "An experimental study on the bending capacity of prestressed concrete beams strengthened with carbon fiber reinforced polymer", China Civil Engineering Journal, vol. 38, no. 11, pp. 9-13, 2005.

[3] R. Wang, X. Yan, and Y. Bai, "Study on the Experiment of Full-size Real Bridge Strengthened with Section Increment and Carbon Fiber Sheets", Journal of Hebei University of Technology, vol. 33, no. 3, pp. 59-63, 2004.

[4] Y. Wang, S. Meng, and H. Jia, "Inverted arch deflection analysis for reinforced concrete beams strengthed by external prestrssing", Journal of Southeast University, vol. 37, no. 6, pp. 1032-1035, 2007.

[5] H. Jiang, F. Huang, and D. Hui, "Experimental research on the service performance of simple-bearing T-type beams reinforced by externally prestressed tendon", Industrial Construction, vol. 40, no. 6, pp. 74-78, 2010.

\section{(C) 2017 / LXet al.}

This is an open access article distributed under the terms of the Creative Commons Attribution 4.0 International Public License (CC-BY 4.0), a copy of which is available at: https://creativecommons.org/licenses/by/4.0/legalcode. This license permits unrestricted use, distribution, and reproduction in any medium, provided the original author and source are credited. 